\title{
Behavior of multiple shear bands in Zr-based bulk metallic glass
}

\author{
L.F. Liu ${ }^{\text {a }}$ L.H. Dai ${ }^{\text {a } *}$, Y.L. Bai ${ }^{\text {a }}$, B.C. Wei ${ }^{\text {b }}$, J. Eckert ${ }^{\mathrm{c}}$ \\ ${ }^{a}$ State Key Laboratory of Nonlinear Mechanics (LNM), Institute of Mechanics, Chinese Academy of Science, Beijing 100080, PR China \\ $\mathrm{b}$ National Laboratory of Microgravity, Institute of Mechanics, Chinese Academy of Science, Beijing 100080, PR China \\ ${ }^{\mathrm{c}}$ Department of Materials and Geosciences, Physical Metallurgy Division, Darmstadt University \\ of Technology, Petersenstr. 23, D-64287 Darmstadt, Germany
}

Received 27 July 2004

\begin{abstract}
The deformation behavior of $\mathrm{Zr}_{41.2} \mathrm{Ti}_{13.8} \mathrm{Cu}_{12.5} \mathrm{Ni}_{10} \mathrm{Be}_{22.5}$ bulk metallic glass was studied by in situ scanning electron microscopy (SEM) quasi-static uniaxial compression tests at room temperature. Multiple shear bands were observed with a large plasticity. Microscopic examination demonstrates that slipping, branching and intersecting of multiple shear bands are the main mechanisms for enhancing the plasticity of this metallic glass. Additionally, nano/micro-scale voids and cracks at the intersecting sites of shear bands and preferential etching of shear bands were observed as well. These observations demonstrated that the formation of shear bands in bulk metallic glasses is resulted mainly from local free volume coalescence.
\end{abstract}

(C) 2005 Elsevier B.V. All rights reserved.

Keywords: Metallic glasses; Ductility; Shear band; Etch

Recently, bulk metallic glasses (BMGs) have attracted large interest due to their unique physical, mechanical and chemical properties [1-6]. However, BMGs loaded under unconstrained conditions usually fail catastrophically with little global plasticity. This deformation behavior has limited the application of BMGs as engineering material so far. At low temperatures (well below the glass transition), plastic deformation of BMGs is usually localized into thin shear bands [7]. Many macroscopic mechanical properties (e.g. plasticity and ductility) are, thus, controlled by the individual and collective behavior of the shear bands. Therefore, the initiation and propagation of localized shear bands in metallic glasses has been the subject of both theoretical and experimental investigation for number of years [8-18]. However, the precise nature of initiation and propagation of shear bands as well as the possible mechanisms for enhancing the plasticity of BMGs still remain uncertain.

In the present letter, the plastic deformation behavior of $\mathrm{Zr}_{41.2} \mathrm{Ti}_{13.8} \mathrm{Cu}_{12.5} \mathrm{Ni}_{10} \mathrm{Be}_{22.5}$ bulk metallic glass is investi-

\footnotetext{
* Corresponding author. Tel.: +86106261 6852; fax: +861062561284.

E-mail address: 1hdai@1nm.imech.ac.cn (L.H. Dai).
}

gated by in situ scanning electron microscopy (SEM) quasistatic uniaxial compression experiments at room temperature. The mechanisms for enhancing the plasticity in this alloy are elucidated. The observed nano/micro-scale voids and cracks at the intersecting sites of shear bands as well as the preferential etching of shear bands provide some evidences to support the free volume theory of the formation of shear bands in metallic glasses $[12,13]$.

$\mathrm{Zr}_{41.2} \mathrm{Ti}_{13.8} \mathrm{Cu}_{12.5} \mathrm{Ni}_{10} \mathrm{Be}_{22.5}$ bulk metallic glass was produced by arc melting the pure elements together under a purified $\mathrm{Ar}$ atmosphere in ingots of the desired composition, each ingot was then re-melted twice to ensure a homogeneous composition. From these ingots $8 \mathrm{~mm}$ diameter rods of metallic glass were prepared by suction casting the molten alloy into a copper mold. The cylinders, thus obtained were confirmed to be non-crystalline by conventional X-ray diffraction.

The samples were machined into dog bone-like shape to ensure that the deformation occurs in the middle constraint region of the specimen. The dimensions of the deformation region are $2.0 \mathrm{~mm} \times 2.0 \mathrm{~mm} \times 1.0 \mathrm{~mm}$. For microscopic observations, the deformed regions of the samples were 


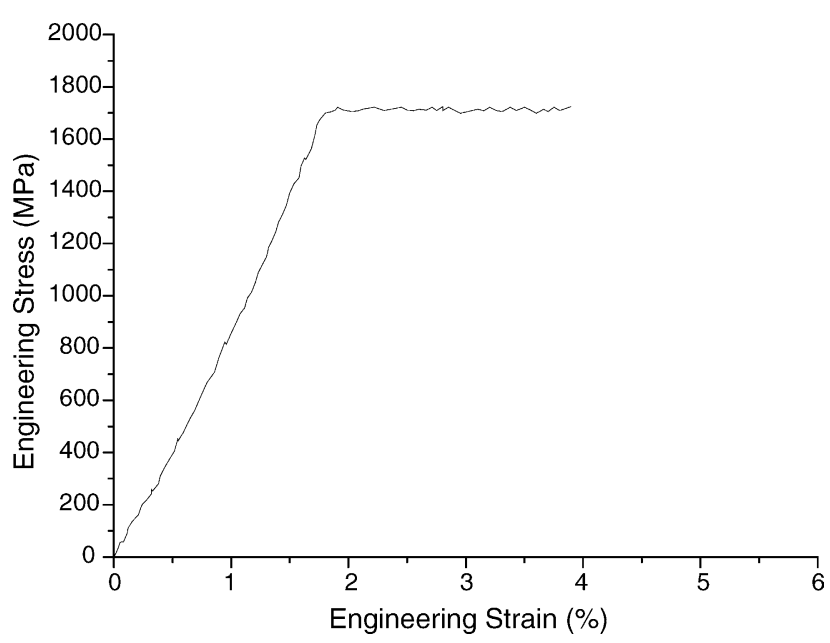

Fig. 1. Stress-strain curve for a $\mathrm{Zr}_{41.2} \mathrm{Ti}_{13.8} \mathrm{Cu}_{12.5} \mathrm{Ni}_{10} \mathrm{Be}_{22.5}$ bulk metallic glass sample tested in quasi-static uniaxial compression.

electro-polished in methanol solution containing 33 vol.\% $\mathrm{HNO}_{3}$. In situ quasi-static uniaxial compression tests were performed in a scanning electron microscope equipped with a loading stage at a strain rate of $4 \times 10^{-5} \mathrm{~s}^{-1}$ at room temperature. The strains were measured with strain gages placed directly on the back surfaces of the samples. The fine structure of the shear bands was examined by SEM (FEI-Sirion NC microscope).

Fig. 1 shows a typical stress-strain curve for a $\mathrm{Zr}_{41.2} \mathrm{Ti}_{13.8} \mathrm{Cu}_{12.5} \mathrm{Ni}_{10} \mathrm{Be}_{22.5}$ sample tested in quasi-static uniaxial compression. All samples were tested until failure. The tests on other samples show similar results, although there is some scatter (within $0.5 \%$ ) in the plastic strain measurement. The deformation behavior is approximately perfectly elastic-plastic, with approximately $2 \%$ elastic strain and a flow stress of about $1700 \mathrm{MPa}$. Serrated flow is apparent in the plastic region. In contrast to little plasticity in tensile tests [19] there is about $2 \%$ plastic flow in the present quasi-static uniaxial compression tests.

During the loading, the deformation processes of the polished surfaces of the samples were monitored by SEM and special care was taken to examine localized shear bands. When the load is below $1000 \mathrm{MPa}$, the compressive deformation is uniform and no shear bands can be detected by SEM. With continuously increasing compression load, shear bands initiate solely at the edge of the sample and propagate along a direction deviating about $2^{\circ}-3^{\circ}$ (about $43^{\circ}$ ) from the maximum shear stress direction $\left(45^{\circ}\right.$ inclined to the loading direction). This deviation is consisted with Zhang et al. result [18]. With increasing strain to about $2 \%$, the neighboring shear bands begin to intersect each other. After the shear bands intersect, their further propagation becomes very difficult. Instead of a single dominant shear band leading to failure as it is typical for tensile testing [19], multiple shear bands with intersecting, branching and slipping are observed in the present compression tests. The typical pattern of multiple shear bands formed at the strain 3.8\% is shown in Fig. 2.
Macroscopically, the material shows an obvious plasticity. This multiple shear banding behavior has also been observed previously in other metallic glasses [20,21]. After failure, the fracture surfaces of the samples show a typical vein pattern.

In order to gain a further understanding of the mechanisms leading to the enhanced plasticity by multiple shear bands in BMGs, the fine structure of the developed shear bands was carefully examined by SEM. Fig. 2 shows a typical deformation pattern with intersecting shear bands. The black arrows indicate the loading direction. The micrograph reveals that multiple intersecting shear bands were formed and they propagate along a direction deviating by $2^{\circ}-3^{\circ}$ from the maximum shear stress direction of $45^{\circ}$. The deviation of the directions of the shear bands from the maximum shear stress plane demonstrates that normal stresses affect the failure of the bulk metallic glass [18]. Furthermore, one can see that the material was sheared-off into many blocks by the intersecting shear bands. When shear bands were interrupted by each other at their intersection sites, their propagation was blocked. This blocking behavior prevents the BMG from fracturing quickly along a single shear band. In other words, the formation of intersecting shear bands can enhance the plasticity of bulk metallic glasses.

To understand the micro-mechanisms responsible for the enhanced plasticity by multiple shear bands, the fine structure of the intersection sites of the shear bands was examined by SEM. Two types of intersection sites can be observed (Fig. 2). One type is formed by branched shear bands (marked in Fig. 2 by A) and the other is the site formed by un-branched shear bands (marked in Fig. 2 by B). These different sites are shown at larger magnification in Fig. 3A and B, respectively. It can be seen from Fig. 3A, that the slip deformation at the typeA intersection site is accommodated by a series of small slip steps. The ratio of the width of the slip steps to that of the shear bands, namely the shear strain, is about 3 . In contrast, Fig. 3B reveals that the slip deformation at the type-B intersection site is accommodated by a single large slip step and the ratio of the width of the slip step to that of the shear band is about 12. Furthermore, from Fig. $3 \mathrm{~A}$ and B, one can find that two kinds of defects form at these two types of intersection sites

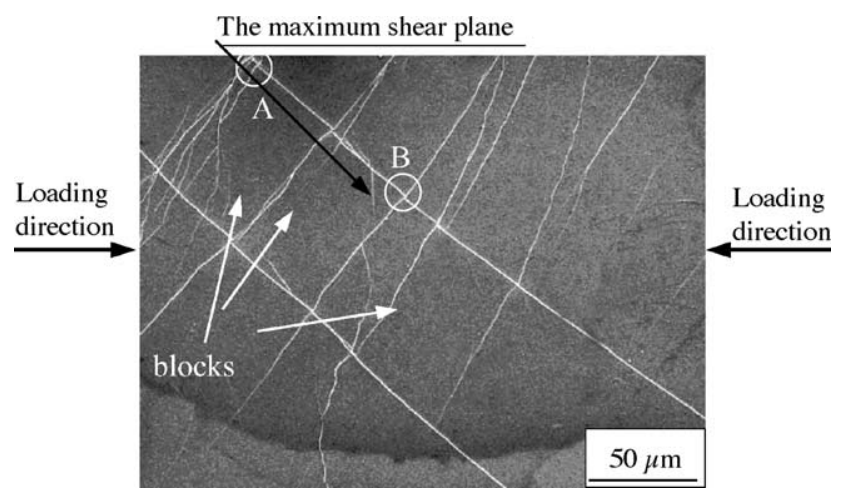

Fig. 2. Typical deformation pattern with intersecting and branched shear bands. 

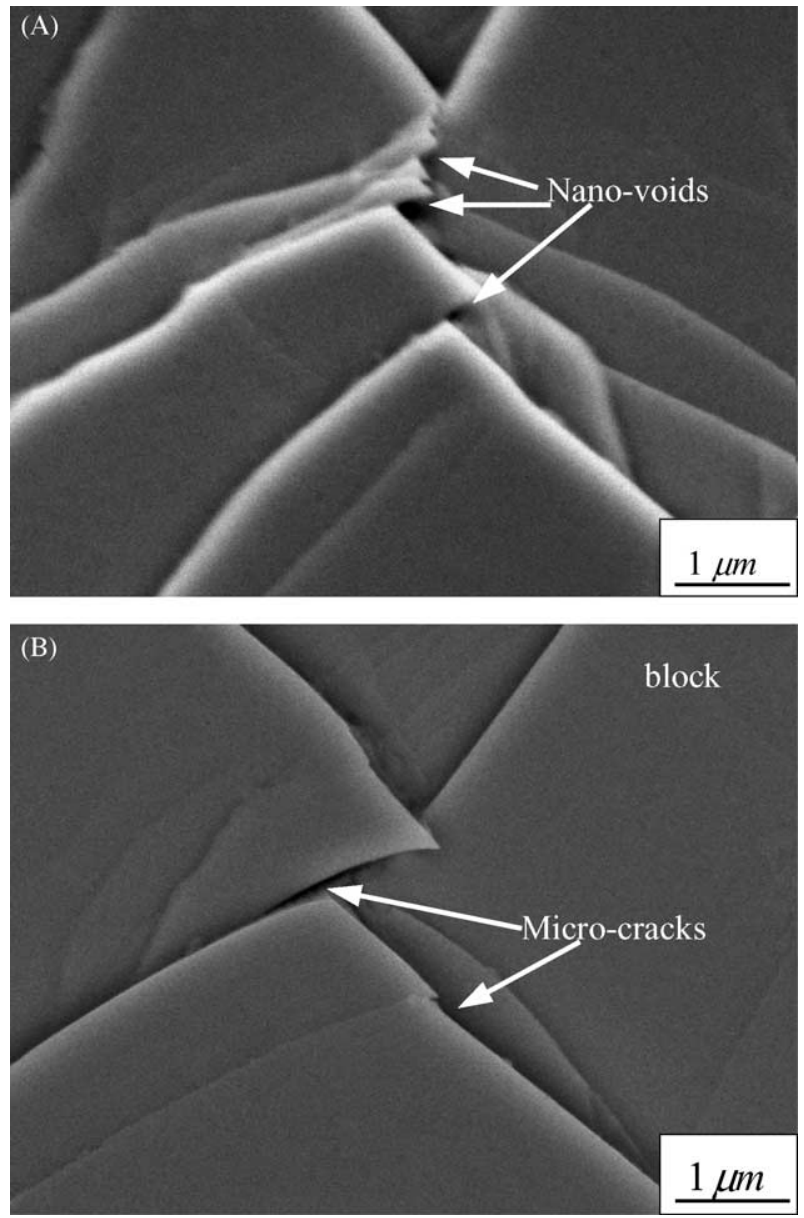

Fig. 3. (A) Micrograph of the intersection site formed by multiple branched shear bands and (B) micrograph of the intersection site formed by unbranched shear bands.

namely, nano-scale voids at site A and micro-scale cracks at site B. From these observations, one can infer that the branched shear bands may distract a larger plastic strain than the un-branched shear bands.

Nanometer-scale voids in shear bands in a Be-free $\mathrm{Zr}$ based bulk metallic glass were recently found by Hufnagel and co-workers [16]. Different from their finding, nano/micro-scale voids and cracks were observed at the intersection sites of the shear bands in the present work. The appearance of the voids and cracks (Fig. 3A and B) at the intersection sites demonstrates that there exists a tension stress state around these sites. This tensile stress state may be produced by the coalescence and dilation of the free volume in the shear bands.

Apart from nano/micro-scale voids and cracks, preferential etching of the shear bands was observed in the present bulk metallic glass, as shown in Fig. 4. The etching phenomenon was first discovered by Pampillo in $\mathrm{Pd}-\mathrm{Cu}-\mathrm{Si}$ metallic glass [7]. However, the etching behavior of shear bands in Zr-based bulk metallic glasses was not reported so far. The etching of shear bands means that the chemical potential within the band has been changed with respect to the rest

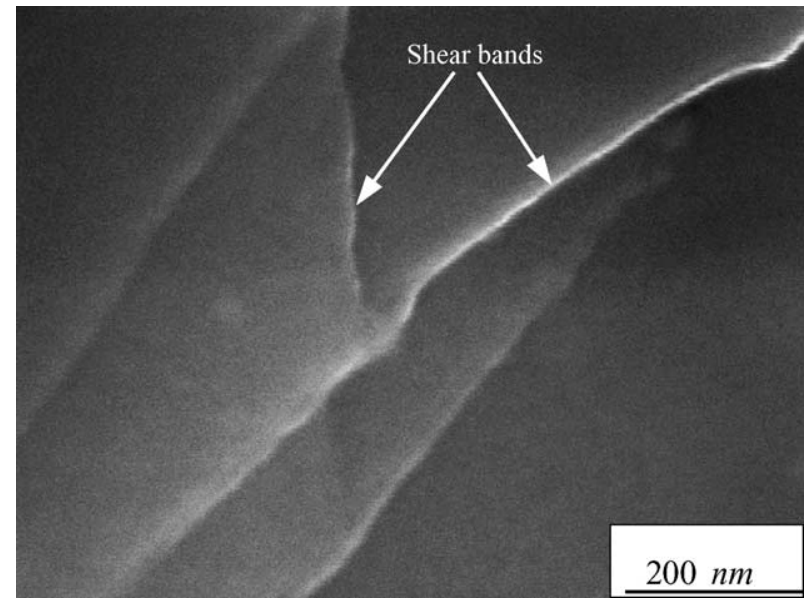

Fig. 4. SEM micrograph revealing the preferential etching of shear bands.

of the material, and this change may be related to a change in structure induced by plastic deformation. As previously suggested [22], this change can yield a more "disordered structure" by destroying the "short-range ordered structure" in the glass and can lead to localized plastic deformation. Based on the existing evidence that generation and coalescence of free volume leads to the formation of nano voids in shear bands [16], the reason for the formation of a "disordered structure" can be interpreted in the framework of the free volume theory $[12,13]$. In shear bands, the increased free volume destroys the "cages" of the free volume sites and the "short-range ordered structure", and then a "disordered structure" in the shear bands will finally form. Therefore, both the etching behavior of the shear bands and the appearance of the nano/micro-scale voids and cracks in the shear bands provide evidence that the formation of shear bands in bulk metallic glasses under quasi-static loading and low-temperature conditions is mainly induced by a local free volume coalescence.

In conclusion, the deformation behavior of $\mathrm{Zr}_{41.2} \mathrm{Ti}_{13.8} \mathrm{Cu}_{12.5} \mathrm{Ni}_{10} \mathrm{Be}_{22.5}$ bulk metallic glass was studied by in situ SEM quasi-static uniaxial compression experiments at room temperature. A large plasticity was achieved by the generation of multiple shear bands. The results demonstrate that intersecting, branching and slipping of shear bands are the main mechanisms responsible for the plasticity enhancement. The observed nano/micro-scale voids and cracks at the intersection sites of the shear bands and the etching behavior of the shear bands are consistent with the free volume theory of shear banding in metallic glasses.

\section{Acknowledgements}

The authors gratefully acknowledge the financial support of this work by the National Natural Science Foundation of China through grants 10472119 and 10232040. 


\section{References}

[1] A.L. Greer, Science 267 (1995) 1947.

[2] W.L. Johnson, MRS Bull. 24 (1999) 42.

[3] A. Inoue, Acta Mater. 48 (2000) 279.

[4] H.S. Chen, Acta Metall. 22 (1974) 1505.

[5] C.T. Liu, M.F. Chisholm, M.K. Miller, Intermetallic 10 (2002) 1105

[6] W.H. Wang, C. Dong, C.H. Shek, Mater. Sci. Eng. R 44 (2004) 45.

[7] C.A. Pampillo, Scripta Mater. 6 (1972) 915.

[8] U. Kühn, J. Eckert, N. Mattern, L. Schultz, Appl. Phys. Lett. 80 (2002) 2478.

[9] W.H. Wang, P. Wen, D.Q. Zhao, M.X. Pan, T. Okada, W. Utsumi, Appl. Phys. Lett. 83 (2003) 3284.

[10] J.J. Kim, Y. Choi, S. Suresh, A.S. Argon, Science 295 (2002) 654.

[11] C.H. Shek, G.M. Lin, Mater. Lett. 57 (2003) 1229.
[12] F. Spaepen, Acta Metall. 25 (1977) 407.

[13] A. Argon, Acta Metall. 27 (1979) 47.

[14] P.E. Donvan, W.M. Stobbs, Acta Metall. 29 (1981) 1419

[15] C.C. David, C.M. Chong, Mater. Sci. Eng. A 318 (2001) 313.

[16] J. Li, F. Spaepen, T.C. Hufnagel, Philos. Mag. A 82 (2002) 2623.

[17] Z. Bian, G. He, G.L. Chen, Scripta Mater. 46 (2002) 1071.

[18] Z.F. Zhang, G. He, J. Eckert, L. Schultz, Phys. Rev. Lett. 91 (2003), 045505 .

[19] C.T. Liu, L. Heatherly, D.S. Easton, C.A. Carmichael, J.H. Schneibel, C.H. Chen, J.L. Wright, M.H. Yoo, J.A. Horton, A. Inoue, Metall. Mater. Trans. A 29 (1998) 1811.

[20] Y. Yokoyama, K. Yamano, K. Fukaura, H. Sunada, A. Inouoe, Mater. Trans. 42 (2001) 623.

[21] G. He, J. Eckert, W. Löser, L. Schultz, Nat. Mater. 2 (2003) 33.

[22] D.E. Polk, D. Turnbull, Acta Metall. 20 (1972) 493. 